\title{
Proposta de fluxograma para design de interfaces digitais: um exemplo prático de como transformar informações de projeto em requisitos de função e conteúdo.
}

Flowchart proposal for design of digital interfaces: a pratical example about how to turn project's informations in requires of function and content.

TEIXEIRA, Júlio M.; Dr; Universidade Federal de Santa Catarina

julio.teixeira@ufsc.br

HENRIQUE, Caroline D.; Mestranda; Universidade Federal de Santa Catarina

carol.dauf@gmail.com

BRAGLIA, Israel A.; Dr; Universidade Federal de Santa Catarina

israelbraglia@gmail.com

GONÇALVES, Berenice S.; Dra; Universidade Federal de Santa Catarina

berenice@cce.ufsc.br

\section{Resumo}

No contexto de design, especificamente na gestão do projeto, a sistematização de processos de forma clara pode ajudar toda a equipe a compreender melhor o contexto e desenvolver soluções satisfatórias, inclusive em projetos de interfaces digitais. Neste sentido, o artigo apresenta, a partir da revisão de literatura, um fluxograma para definir requisitos funcionais e de conteúdo no projeto de interfaces. Para a revisão de literatura foi realizado um levantamento assistemático em diferentes bases de dados. Aos achados deste levantamento, foram acrescidos ainda artigos e livros previamente considerados relevantes para sustentação da proposta. Como resultado, o fluxograma para interfaces digitais é apresentado de forma detalhada, como também uma amostra de uso a partir de uma aplicação empírica. Acredita-se que o fluxograma proposto possa contribuir para a área em que o estudo se insere, além de ter aplicação imediata no mercado.

Palavras Chave: gestão visual; fluxograma; interfaces digitais.

\begin{abstract}
In the design context, specifically in design project management, systematizing processes in a clear and objective way may assist working teams to better understand the context and offer appropriate solutions, inclusive for digital interfaces projects. In this sense, this article presents, based on a literature review, a flowchart to set functional requirements and content for project interfaces. Data was collected from different databases, and seminal articles and books in the area were added to support the study. As a result, the flowchart for digital interfaces is presented in the detailed way and, as well as a sample of its use, through an empirical application. It is believed that the flowchart proposed may contribute to the research area it is inserted, besides a practical application in the work market.
\end{abstract}

Keywords: visual management; flowchart; digital interfaces. 


\section{Introdução}

No contexto de design, especificamente na gestão do projeto, estruturar processos de forma clara pode ajudar toda a equipe a compreender melhor o contexto e a desenvolver soluções satisfatórias, inclusive em projetos de interfaces digitais. Alimentar informações de projeto em um fluxo lógico pode ser o primeiro passo para reduzir a complexidade e deixar as atividades e a tomada de decisões mais claras, lógicas e visuais (TEIXEIRA, 2018).

Os fluxogramas são representações visuais também presentes na área de Design, Mídia e Gestão, que se tornam importantes aliados para o planejamento de interfaces, a exemplo da estrutura de navegação. Seu potencial semântico favorece uma rápida compreensão da conexão entre as etapas além de proporcionar a organização, o entendimento da relação e da importância de cada informação. Torna-se este um suporte desejável para a tomada de decisões. Diferentes pesquisas e conteúdos técnicos já foram publicados no âmbito de estratégias para organização e representação das informações na gestão de projetos. Cabe destacar: Eppler e Platts (2009), Sibbet (2013), Finocchio Júnior (2013), Galsworth (2005) e Teixeira, Benedet e Hoppe (2015). Este último apresenta como principal contribuição um passo a passo que ajuda a definir o peso dos requisitos de projeto a partir de personas e demais pesquisas informacionais.

Tem-se como objetivo neste artigo, apresentar uma nova proposta de fluxograma para interfaces digitais que transforma as informações provenientes da pesquisa informacional em requisitos de função e conteúdo. Também será apresentado um exemplo aplicado que visa demonstrar seu uso.

Pressupõe-se que a apresentação sistêmica de um fluxograma tende a facilitar de forma prática a conexão de etapas do desenvolvimento de projetos de interfaces. Auxiliando na visualização das relações entre as informações e a importância de cada informação tem na tomada de decisão ${ }^{1}$, tanto para analistas como pesquisadores e, principalmente, para designers que atuam no desenvolvimento de novas interfaces e na análise das interfaces existentes.

\section{Revisão da Literatura}

Diferentes pesquisas, métodos, modelos e práticas relacionadas ao desenvolvimento de projeto detalham atividades para auxiliar a pesquisa informacional do projeto. Entre eles cabem citar: Rozenfeld (2005); Back (2008); PMI (2011) - PMBOK, Teixeira (2015) e Teixeira (2018). Teixeira $(2015,2018)$ aborda princípios e ferramentas e propõe modelos de gestão visual para promover maior visualização ao processo de desenvolvimento de projetos. Em outro trabalho o mesmo autor, em cooperação com outros dois pesquisadores (TEIXEIRA, BENEDET e HOPPE, 2015), amplia o valor dessa abordagem de visualizar o projeto de forma panorâmica ao apresentar um passo a passo de como definir requisitos utilizando personas e pesquisas informacionais.

Pode-se ainda alinhar tais abordagens projetuais aos conceitos de usabilidade, como também ao uso de recursos no contexto de projeto, e na avaliação e desenvolvimento de soluções em interfaces de produtos. Bonsiepe $(1997,2015)$ já argumentava que cabe ao design contribuir no estudo da interface familiarizando-se com o objeto e o usuário, adaptando as características

${ }^{1}$ Isso pode ser trabalhado desde o levantamento de informações iniciais até a avaliação da interface em diferentes planos projetuais. 
físicas e cognitivas deste. Convergindo com a colocação do autor supracitado, pode-se entender que as informações de projeto (quanto aos objetos e as características do usuário) podem ser utilizadas como insumos para a tomada de decisões. Neste caso, a colocação de Krippendorf (1989) ganha ainda mais sentido quando este afirma que: "as coisas devem ter forma para serem vistas, mas devem fazer sentido para serem entendidas e usadas".

A cerca do desafio de projetar interfaces para distintos usuários, Freitas (2005) destaca que a interface se torna um meio onde trafegam linguagens decodificáveis que devem, de alguma forma, sensibilizar indivíduos chamando-os para a interação. Avaliar estes elementos que interpõe e compõe com diferentes graus de importância dentro de um sistema requer preliminarmente identificar perfis dos possíveis usuários, atribuindo diferentes pesos cada perfil e posteriormente para cada critério pré-estabelecido, contribuindo assim para uma ponderação lógica e fundamentada (TEIXEIRA, BENEDET e HOPPE, 2015).

Desta forma, mostra-se relevante apresentar mecanismos, princípios e soluções que auxiliem a análise e o desenvolvimento de interfaces de forma mais sistemática e visual. Os principais temas e autores que nortearam o desenvolvimento da solução são expostos a seguir:

Quadro 1 - Principais publicações que nortearam a proposta.

\begin{tabular}{ll}
\hline Autor (ano) & O que foi proposto/pesquisado \\
\hline Rozenfeld (2005) & $\begin{array}{l}\text { Apresenta um modelo de estruturação e gestão do processo de desenvolvimento de produtos } \\
\text { que pode ser adaptado a diferentes tipos de abordagem. }\end{array}$ \\
\hline Garrett (2010) & $\begin{array}{l}\text { Propõe um método que serve para auxiliar na idealização da experiência do usuário por meio } \\
\text { de cinco planos. }\end{array}$ \\
\hline $\begin{array}{l}\text { Eppler e Platts } \\
\text { (2009) }\end{array}$ & $\begin{array}{l}\text { Propõe práticas visuais para capturar e descrever atividades do processo de gerenciamento } \\
\text { estratégico organizacional. }\end{array}$ \\
\hline $\begin{array}{l}\text { Sibbet (2013) } \\
\text { Apresenta técnicas e ferramentas para desenvolvimento do pensamento visual como estratégia } \\
\text { de percepção, engajamento e motivação de equipes de projeto. }\end{array}$ \\
$\begin{array}{ll}\text { Burkolter et al } \\
\text { (2014) }\end{array}$ & $\begin{array}{l}\text { Colocam a personalização de interfaces para o usuário como caminho para reduzir erros e } \\
\text { aprimorar a aceitação. }\end{array}$ \\
\hline $\begin{array}{l}\text { Teixeira (2015) e } \\
\text { Teixeira (2018) }\end{array}$ & $\begin{array}{l}\text { Aborda princípios da gestão visual no desenvolvimento de projetos e como isso pode auxiliar na } \\
\text { compreensão, visualização, interação pela equipe de projeto. }\end{array}$ \\
\hline $\begin{array}{l}\text { Teixeira, Benedet e } \\
\text { Hoppe (2015). }\end{array}$ & $\begin{array}{l}\text { Apresentam um passo a passo de como definir requisitos de projeto utilizando personas e } \\
\text { demais pesquisas informacionais. }\end{array}$
\end{tabular}

Fonte: Autores (2018)

Cabe destacar que, para Garrett (2010), essa idealização da experiência do usuário (supramencionada no Quadro 1) começa da parte estratégica (e mais abstrata) e aos poucos vai se tornando mais concreta (uma interface). Os cinco planos são denominados por ele como: estratégico, escopo, estrutural, esqueleto e superfície. De forma sucinta podemos dizer que: 
Figura 1 - Os planos de interface propostos por Garret (2010)

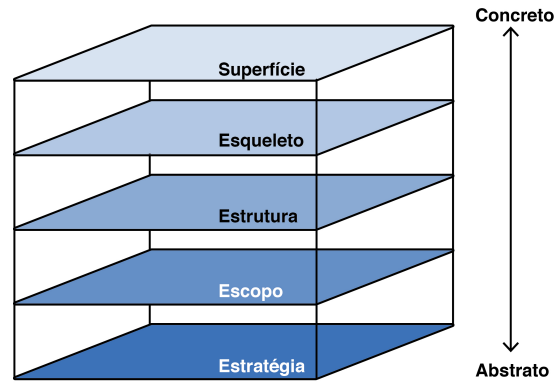

Fonte: Adaptado de Garrett (2010)

Plano Estratégico: visa identificar o que se quer com o desenvolvimento da interface e o que o usuário precisa.

Plano de Escopo: ajuda a transformar o plano estratégico em requisitos, que são desdobrados em recursos para a interface. Neste plano são elencadas funções e conteúdos relacionados a interface.

Plano Estrutural (hierarquia): aqui funções e conteúdos são apresentados segundo uma hierarquia que é estabelecida de acordo com características, aptidões, preferências e necessidades do usuário.

Plano de Esqueleto (wireframes): aqui se torna possível a prototipação da interface. Para isso, deve-se respeitar a hierarquia estabelecida no Plano Estrutural.

Plano de Superfície: neste plano o que foi produzido até então é unido e transformado em telas que servirão de base para a equipe de desenvolvimento e implementação.

O uso dos fluxos de informações são concatenados por meio das matrizes. A matriz de decisão (que será apresentada a seguir) pode auxiliar na avaliação da interface de diferentes planos. Ela pode ser aplicada a partir do plano de escopo até o plano de superfície.

Neste sentido, Teixeira, Benedet e Hoppe (2015) já apresentam o uso combinado de matrizes e personas como uma forma alternativa para situações onde a customização do projeto por perfil de público não se mostra viável ${ }^{2}$.

A alternativa de Teixeira, Benedet e Hoppe (2015) sugere que as diferentes personas representem de forma estereotipada os diferentes perfis de público, e que estas "participem" da tomada de decisões no projeto. Ou seja, cada uma delas deve representar um perfil e, para isso, os autores sugerem que seja atribuído a cada persona um peso para a força do seu perfil. Este será utilizado como fator multiplicador de notas no processo decisório ${ }^{3}$.

A seguir, serão apresentados os materiais e métodos que embasaram uma proposta prática considerando o uso de personas no processo decisório de projetos de interfaces digitais.

\footnotetext{
${ }^{2}$ Por diferentes circunstâncias, a customização do projeto por perfil de público - como é proposto por Burkolter et al (2014) - não se mostra viável. Inclusive, na referida publicação, os autores já indicam alguns exemplos.

${ }^{3}$ Como já foi antecipado, o presente artigo incorpora essa lógica sugerida pelos autores. Ainda que se busque apresentar brevemente tal lógica, caso ao final da leitura ainda não se tenha a compreensão completa do funcionamento desse arranjo, recomendamos a leitura na integra da publicação de Teixeira, Benedet e Hoppe (2015).
} 
Tal proposta surge a partir dos planos de Garrett (2010) e com atenção aos requisitos de função e conteúdo.

\section{Materiais e Métodos}

Esta pesquisa pode ser classificada quanto à natureza como aplicada, pois "objetiva gerar conhecimentos para aplicação prática dirigida à solução de problemas específicos" (SILVA, 2004, p. 14). As proposições que sustentam a proposta sugiram das necessidades práticas e do levantamento bibliográfico realizado durante a revisão da literatura.

Para a revisão de literatura foi realizado um levantamento assistemático em diferentes bases de dados. Cabe esclarecer que para tal levantamento, foram utilizadas diferentes palavraschave e em diferentes momentos, a medida que se buscava sustentação para lacunas específicas da proposta, por isso, a forma "assistemática". Aos achados destes levantamentos foram acrescidos ainda, como base para sustentação da proposta, artigos e livros previamente considerados relevantes pelos pesquisadores e pela literatura. As principais publicações que sustentaram a proposta estão apresentadas na revisão de literatura (ver Quadro 1).

Após isso, decidiu-se adaptar o fluxograma de Teixeira, Benedet e Hoppe (2015) e aplicá-lo de forma empírica em uma situação real para: a) ilustrar o uso da proposta; e b) perceber oportunidades de melhorias no fluxograma. No entanto, decidiu-se por não o denominar aqui como estudo de caso pois, a estrutura da publicação não permitiria ao mesmo tempo descrever com uma maior riqueza de detalhes a proposta e a situação-caso. Portanto, será apresentada a situação de aplicação apenas como exemplo prático ilustrativo.

\section{Resultados}

Com base na literatura elencada e especialmente a partir de Garrett (2010) e Teixeira, Benedet e Hoppe (2015), foi desenvolvido um fluxograma para interfaces digitais. Este transforma as informações provenientes da pesquisa informacional em requisitos de função e conteúdo. Para acompanhar a ferramenta em uso, esta foi utilizada em nove projetos práticos.

Como dito anteriormente, o método Garrett (2010) serve para auxiliar na idealização da experiência do usuário por meio de cinco planos. Integrada a esses planos, a proposta de Teixeira, Benedet e Hoppe (2015) apresenta um passo a passo para definir requisitos de projeto utilizando personas e demais pesquisas informacionais.

Observou-se nesta proposta que o levantamento de informações e análise dos dados de forma sistematizada, a partir da definição de pesos, são insumos essenciais para construção de um projeto de interface mais sólido as características e as necessidades das persona ${ }^{4}$.

\subsection{Etapas do Fluxograma para Interfaces Digitais}

Para a estruturação do fluxograma foram avaliadas, em primeira instância, diferentes práticas de pesquisa e de mercado que propõem conectar etapas do desenvolvimento de projeto. As principais publicações que sustentam a proposta foram mencionadas no Quadro 1.

\footnotetext{
4 Para saber o que é persona ou como aplicar essa técnica de forma mais robusta e conectada aos requisitos de projeto, recomenda-se a leitura de Teixeira, Benedet e Pinto (2016) e Teixeira, Benedet e Hoppe (2015). O que é proposto nas referidas publicações alinha-se muito bem ao que é proposto aqui neste artigo.
} 
Nesta proposta, algumas questões preliminares antecedem os cinco planos sugeridos por Garrett (2010). Perceba também que no primeiro plano inclui-se (M) para Mercado (Pú) para Público e (Pr) para Produto, conforme sugerem Teixeira, Benedet e Hoppe (2015) e que será melhor esclarecido a seguir. Essas informações podem ser utilizadas em diferentes planos, principalmente, a partir do plano de escopo. Cabe lembrar que o primeiro autor divide esses planos em: estratégico (PE), escopo (S), estrutural (St), esqueleto (Es) e superfície (Sp). A nível macro, a base da proposta se apresenta desta maneira (Fig. 2).

Figura 2 - Base da proposta

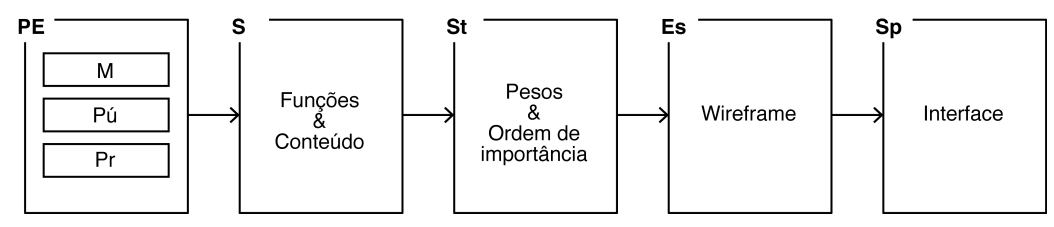

Fonte: Desenvolvido pelos autores (2018)

\subsubsection{Levantamento de Informações}

A seguir, são apresentadas as diferentes partes deste fluxograma com destaque para o levantamento de informações nas frentes colocadas por Teixeira Benedet e Hoppe (2015). Estas são definidas como: Mercado (M), Público (Pú) e Produto (Pr).

Figura 3 - Fluxograma para interfaces digitais (Destaque Parte 1- levantamento de informações)
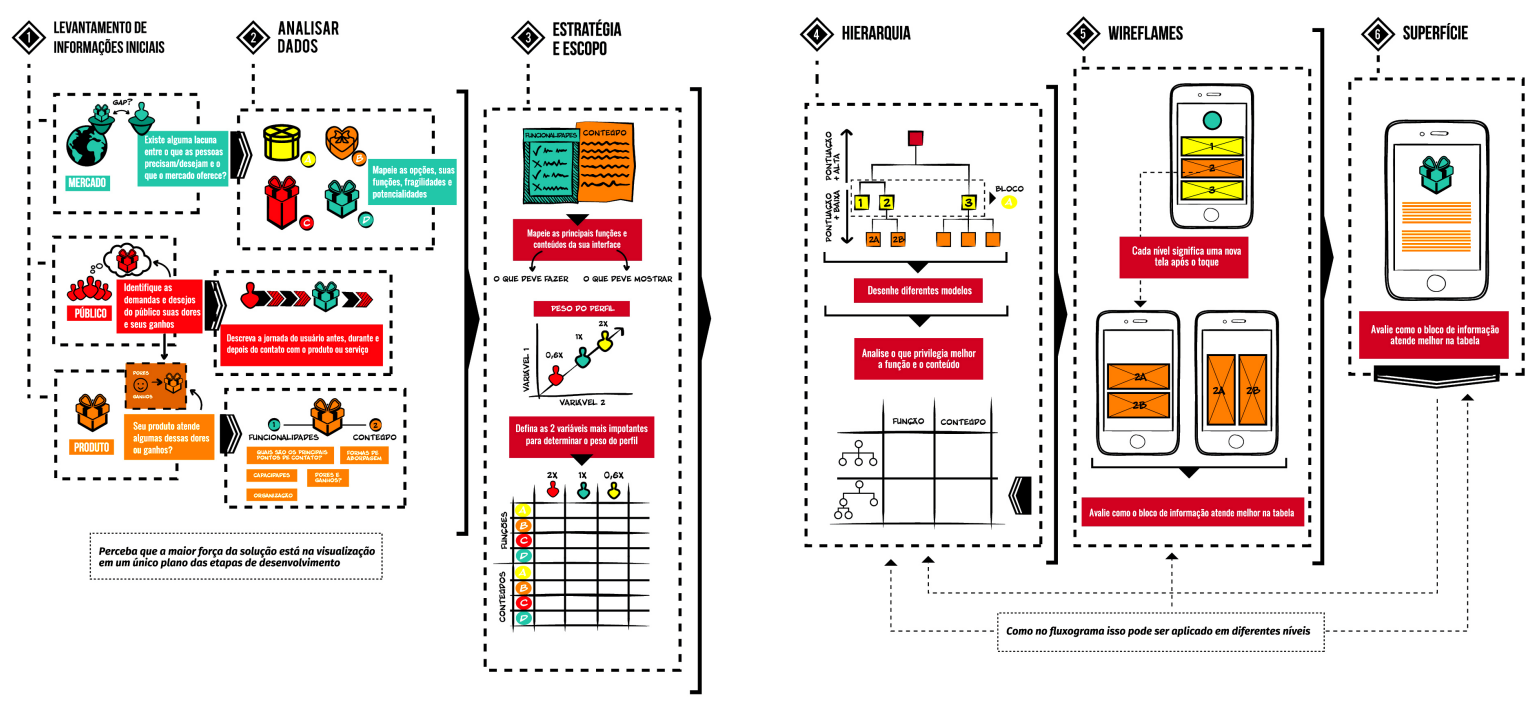

Fonte: Adaptado de Teixeira (2018)

Inicialmente, deve-se buscar informações sobre três frentes essenciais para o desenvolvimento de qualquer projeto: o mercado, o público e o produto. Quanto ao mercado, o objetivo é a busca de dados que demonstrem as principais necessidades, restrições, oportunidades, ameaças e boas práticas. Isso pode auxiliar na idealização de uma interface útil e relevante do ponto de vista mercadológico.

Em relação ao público e às funções do produto ou serviço, deve-se conhecer os potenciais 
usuários e consumidores, considerando suas principais demandas, desejos, expectativas e interesses em relação ao que é oferecido pela organização, o produto e suas interfaces.

As características função e conteúdo da interface (neste caso, a interface é o Produto) a serem desenvolvidas devem ser analisadas. Quando oportuno e viável, sugere-se a realização de entrevistas, análises remotas e a utilização de demais recursos e práticas que possam ajudar a avaliar, a validar ou, ao menos, a respaldar essas informações.

\subsubsection{Análise dos Dados}

Após obter as informações do público e do produto, é possível mapear as oportunidades, as fragilidades e as potencialidades de mercado. Neste momento, pode-se inclusive analisar a jornada do usuário (ou jornada da persona) para identificar como a persona comporta-se antes, durante e depois de ter contato com a interface e os produtos. Na etapa de análise é necessário também observar as principais funcionalidades e o conteúdo que será disponibilizado na interface. Para realizar essa análise podem ser utilizados mapas mentais ou painéis semânticos, por exemplo. É essencial neste momento, tornar a visualização das informações mais fácil.

\subsubsection{Plano Estratégico e Escopo}

É nessa etapa também que são definidas as variáveis e calculados os pesos dos perfis/personas que serão impactadas pela solução proposta. Esse cálculo é fundamental para avançar nas próximas etapas.

Para calcular o peso do perfil das personas, segundo a proposta de Teixeira, Benedet e Hoppe (2015), faz-se necessário primeiramente definir as variáveis que irão nortear o cálculo. Faz-se importante lembrar que são essas variáveis que auxiliarão a avaliar relação da persona com o negócio (elas são determinadas pela equipe de projeto ou pela equipe de analistas). No exemplo abaixo foram escolhidas as variáveis "poder de compra" (eixo x) e "poder de persuasão" (eixo y) pois pessoas que podem influenciar outras pessoas a comprar o produto são muito importantes para esse negócio. Neste exemplo, foram criadas duas personas com nomes fictícios: Carlos e Maria Luiza. Dentro das coordenadas, é possível identificar o peso de Carlos e Maria Luiza. O gráfico mostra neste exemplo que Maria Luiza tem peso 8, enquanto Carlos totalizou em 6.

Figura 4 - Representação das variáveis

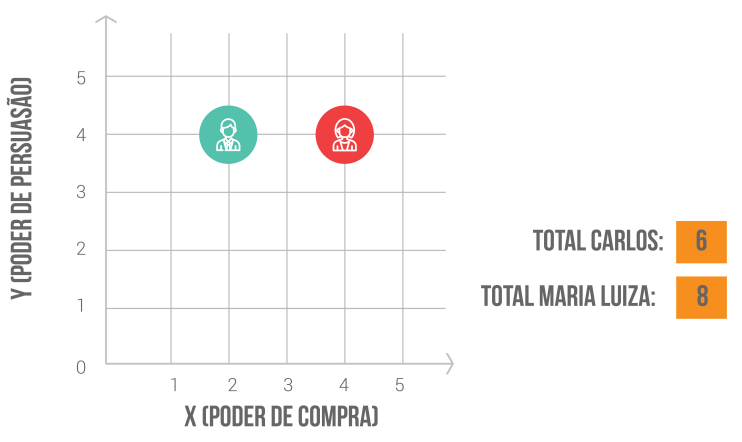

Fonte: Adaptado de Teixeira, Benedet e Hoppe (2015) 
Para esboçar o Plano de Escopo, as personas são fundamentais para definir o peso dos requisitos da interface visual, principalmente do ponto de vista de função e conteúdo. No exemplo, foram divididos itens relacionados e atribuídas notas para cada um deles. Essas notas são definidas a partir das características das personas e da importância que é dada por ela para cada um dos itens. Recomenda-se realizar uma pesquisa prévia para atribuir uma nota fundamentada. Para chegar aos resultados, deve-se multiplicar a nota atribuída ao peso do perfil. Em seguida, somar os resultados calculados em cada um dos itens. Esses números irão mostrar a importância de cada requisito. No exemplo, o pagamento on-line é a função mais importante assim como o depoimento é o item mais relevante no que diz respeito ao conteúdo.

Figura 5 - Atribuição das notas aos perfis

\begin{tabular}{|c|c|c|c|}
\hline Funç̣̄ES & $\begin{array}{c}\text { MARIA LUIZA } \\
\quad X 8\end{array}$ & $\begin{array}{c}\text { CARLOS } \\
X_{6}\end{array}$ & TOTAL \\
\hline PEDIR/GERAR ORÇAMENTO & $5 / 40$ & $2 / 12$ & 52 \\
\hline ACOMPANHAMENTO DO PEDIDO & $3 / 24$ & $5 / 30$ & 54 \\
\hline PAGAMENTO ONLINE & $4 / 32$ & $5 / 30$ & 82 \\
\hline CONTEUÚDO & $\begin{array}{l}\text { MARIA LUIZA } \\
\quad \text { X8 }\end{array}$ & $\begin{array}{l}\text { CARLOS } \\
\times 6\end{array}$ & TOTAL \\
\hline PORTF́́llo & $2 / 16$ & $1 / 6$ & 22 \\
\hline CATÁLOGOS & $3 / 24$ & $2 / 12$ & 36 \\
\hline DEPOIMENTOS & $5 / 40$ & $4 / 26$ & 66 \\
\hline BLOG & $2 / 16$ & $2 / 12$ & 28 \\
\hline
\end{tabular}

Fonte: Autores (2018)

\subsubsection{Plano Estrutural (Hierarquia)}

Após estabelecer as variáveis e calcular o peso das personas, deve-se estabelecer a hierarquia da interface visual da solução proposta. Recomenda-se colocar as funções e conteúdos de maior valor na parte mais superior conforme figura 6. 
Figura 6 - Atribuição das notas a funções e conteúdos

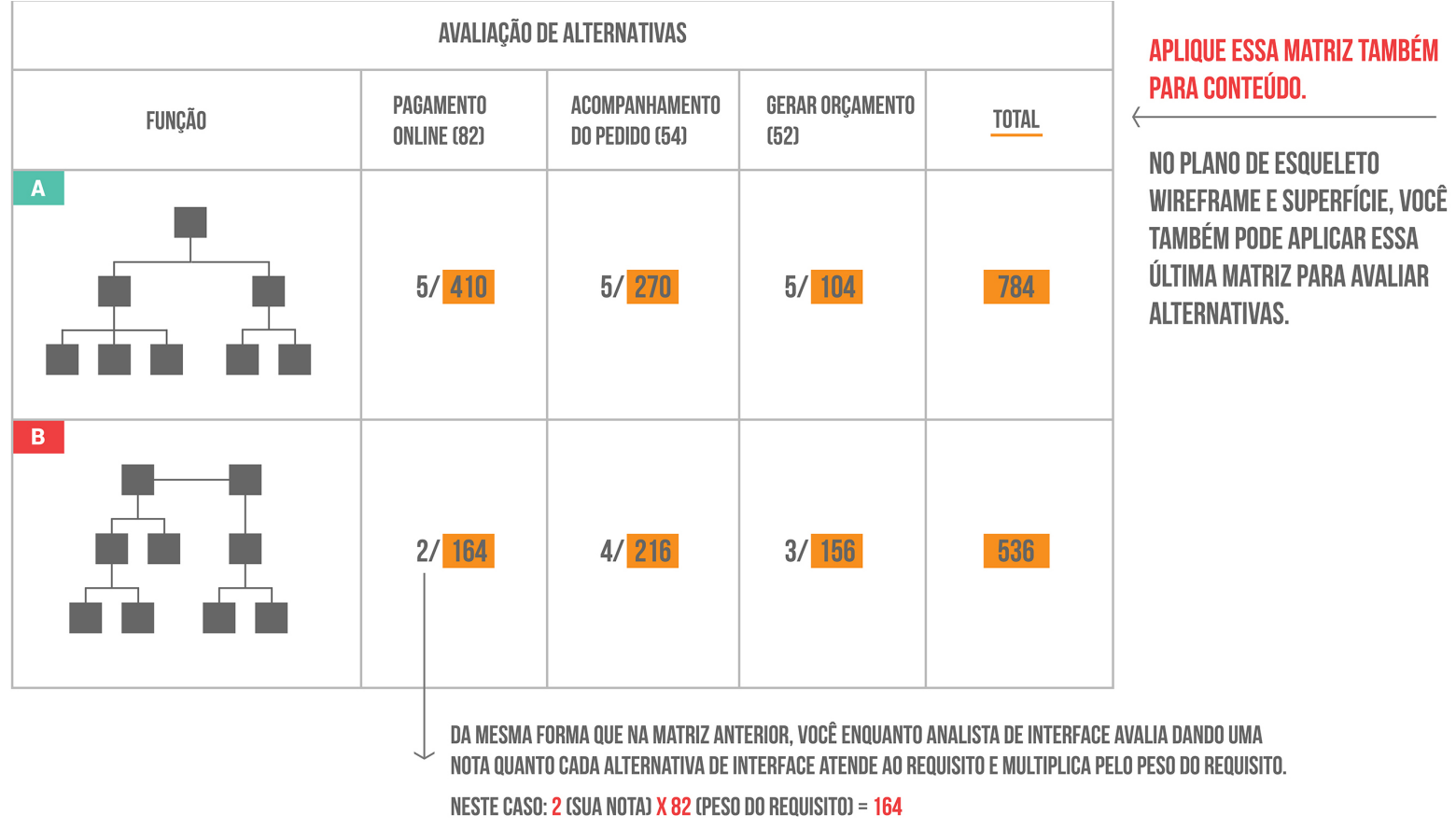

Fonte: Autores (2018)

Da mesma forma que na matriz representada na figura 6, deve-se avaliar, por meio de uma nota, o quanto que cada alternativa de interface atende ao requisito/item listado. A nota atribuída deve ser multiplicada pelo peso do requisito (calculado anteriormente).

\subsubsection{Plano Esqueleto (Wireframe)}

Com base na hierarquia estabelecida, deve-se estruturar o wireframe. Se faz necessária a construção de uma proposta que evidencie os itens de maior pontuação e desenvolva uma interface que corresponda aos anseios das personas. Caso tenha mais de uma opção, pode-se avaliar como as diferentes alternativas de esqueleto atendem os requisitos da tabela (isso pode ser feito da mesma forma que foi descrito no plano estrutural, item 4.1.4).

\subsubsection{Superfície}

Nesta última etapa é possível avaliar como diferentes alternativas de superfície atendem os requisitos da tabela (isso pode ser feito tela a tela da mesma forma que no plano estrutural).

\subsection{Exemplo Prático de Aplicação em uma Empresa Contábil}

No final do ano de 2017, três consultores (dos quais dois são autores do presente artigo) foram selecionados pelo SEBRAE/SC ${ }^{5}$ a prestar consultoria sobre interfaces digitais para nove empresas no estado de Santa Catarina. Todas as consultorias tiveram como base o uso do fluxograma aqui proposto como já mencionado no item 3 "Materiais e Métodos". Ressaltou-se também a impossibilidade de descrever sistematicamente as empresas como estudo de caso. Desta forma, uma das nove empresas foi selecionada apenas para exemplificar como o fluxograma foi aplicado.

\footnotetext{
${ }^{5}$ Serviço Brasileiro de Apoio às Micro e Pequenas Empresas de Santa Catarina
} 
A consultoria a ser descrita foi realizada para uma empresa da área contábil e foi executada em 4 etapas, a saber: (1) diagnóstico, onde foi elaborado o perfil do público que a empresa atende, a criação e validação das personas; (2) análise, onde foi realizada a análise do site da empresa e para este foi proposto a instalação de uma ferramenta de avaliação de interfaces; (3) plano de interface (escopo), onde foi apresentada a matriz de requisitos e o plano de escopos (peso dos requisitos e função dos conteúdos, e por fim, (4) próximos passos, onde foram indicadas as sugestões para os novos procedimentos ao site da empresa. Em razão dos limites do cronograma de atendimento pactuado com a empresa, um aprofundamento mais detalhado da análise de interface não foi aplicado a este estudo. Porém, tendo o tempo como desafio comum deste âmbito, o uso do fluxograma se torna oportuno, enquanto ferramenta de análise enxuta, para oferecer resultados satisfatórios com certa profundidade.

Sendo assim, o exemplo aqui sucintamente relatado expõe como foram realizadas estas etapas no fluxograma. É importante frisar que já existia previamente outro procedimento estabelecido pelos consultores para extrair dados da empresa, porém não é plausível de ser aqui descrito por não ser o foco deste artigo. Todavia, de posse dos dados obtidos, foi realizada a construção das personas. Para essa empresa, duas personas foram criadas e com elas as descrições dos pesos. Apresenta-se a seguir a persona Bianca Lancaster, conforme figura 7:

Figura 7 - Exemplo de uma das Personas definidas

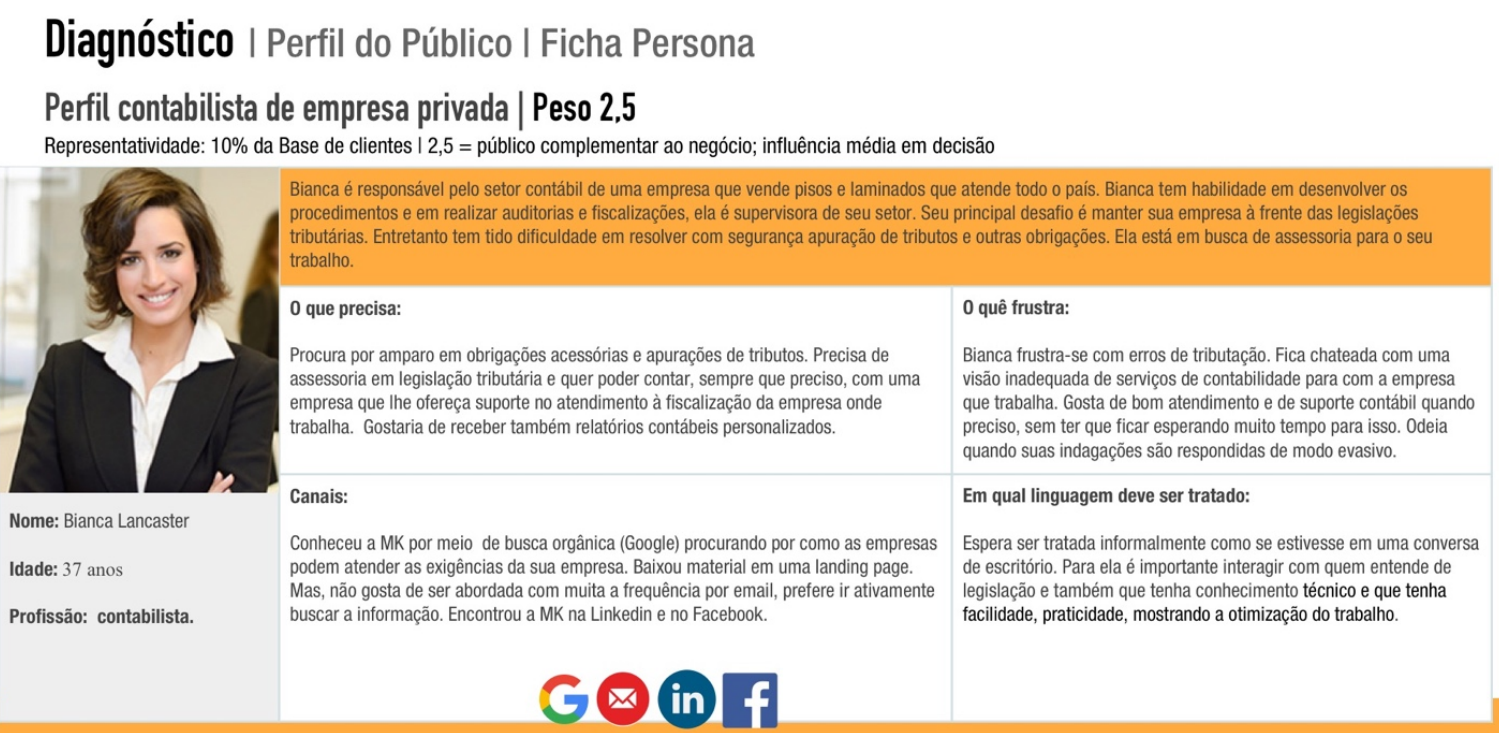

Fonte: Autores (2018)

A persona foi criada conforme a construção de um cenário e a partir deste apresentam-se 4 situações que são: a sua necessidade (o que precisa), o quê frustra, canais e em qual linguagem deve ser tratada. Desta forma, temos para este cenário o seguinte detalhamento: 
Quadro 2 - Descrição do cenário da persona Bianca

\section{Cenário}

Bianca é responsável pelo setor contábil de uma empresa que vende pisos e laminados que atende todo o país. Bianca tem habilidade em desenvolver os procedimentos e em realizar auditorias e fiscalizações. Ela é supervisora de seu setor. Seu principal desafio é manter sua empresa à frente das legislações tributárias. Entretanto, tem tido dificuldade em resolver com segurança apuração de tributos e outras obrigações. Ela está em busca de assessoria para o seu trabalho.

Fonte: Autores (2018)

Após a construção do cenário, foi elencada uma matriz de requisitos com o peso da persona. O peso refere-se ao poder de decisão, compra ou influência da persona sobre o negócio. No caso de Bianca, com base na construção do cenário, ela apresentou um perfil contabilista de empresa privada com peso 2,5 , o que significa que esta persona possui representatividade de $10 \%$ da base de clientes da empresa. Este valor representa um público complementar ao negócio, ou seja, influência média em decisão final. Este processo é mostrado no quadro a seguir:

Figura 8 - Matriz de requisitos da persona

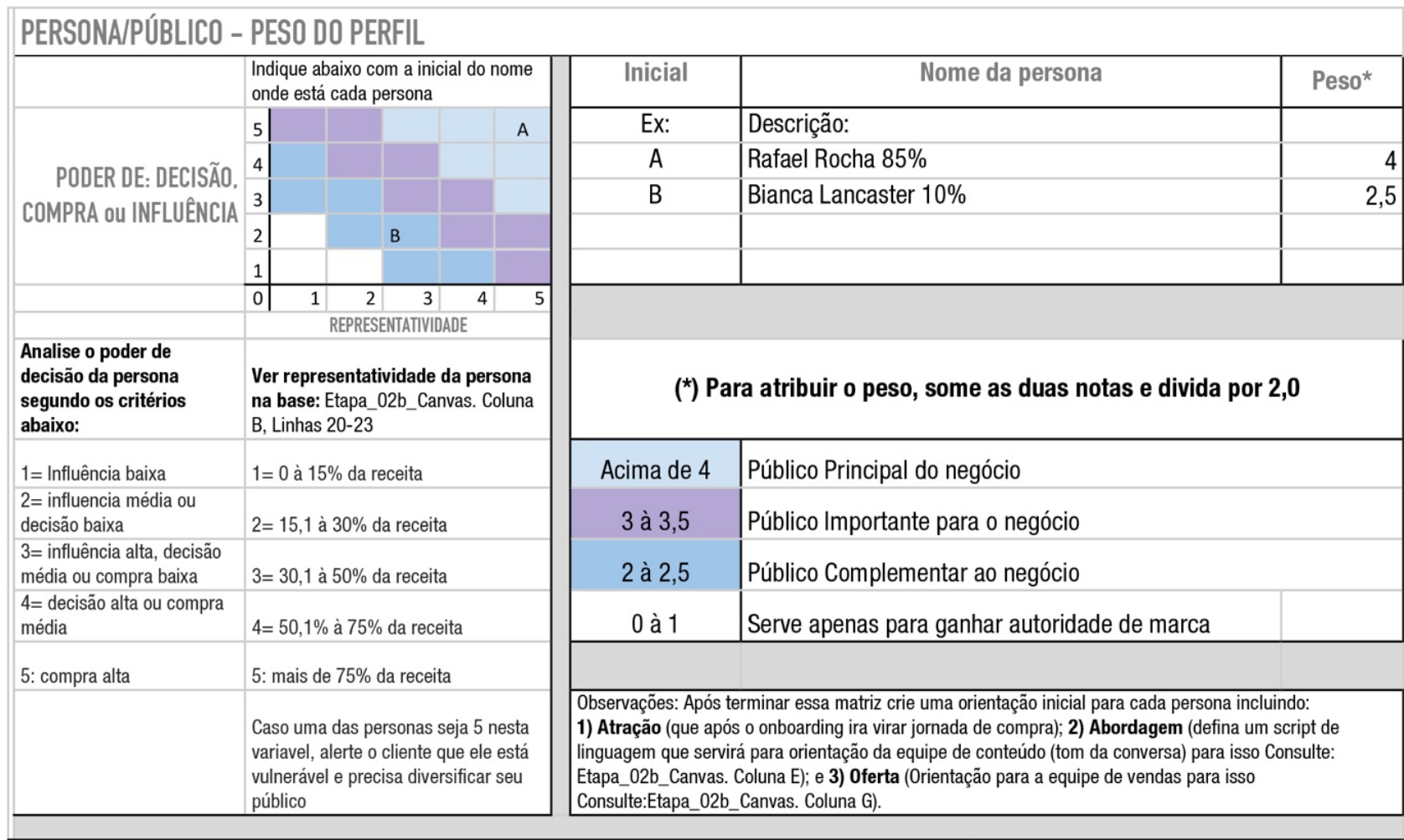

Fonte: Autores (2018)

Conforme a matriz de representatividade exibida na figura 8 , esta mostra o peso das personas. A persona Rafael foi criada pelo mesmo procedimento da persona Bianca. Este quadro serviu de base para a criação da matriz de avaliação da atual interface. Entretanto, para realizar esta matriz é preciso elencar os requisitos da interface, que foram extraídos a partir da pesquisa 
informacional que inclui, entre outros procedimentos, a análise da interface atual. Sendo assim, para este caso, os requisitos são mostrados conforme o quadro a seguir:

Quadro 3 - Requisitos de interface

\begin{tabular}{|c|c|c|c|c|}
\hline & Legibilidade & Responsivo & $\begin{array}{l}\text { Tecnologias } \\
\text { ultrapassadas }\end{array}$ & $\begin{array}{l}\text { SEO (nome da } \\
\text { empresa) }\end{array}$ \\
\hline & Legível & Bom & Não apresenta & Bom \\
\hline Análise & $\begin{array}{l}\text { Bom contraste de cores } \\
\text { e fonte adequada. }\end{array}$ & Bom & Não apresenta & Bom \\
\hline \multirow[t]{2}{*}{ Observações } & $\begin{array}{l}\text { Bom contraste de cores } \\
\text { e fonte adequada. }\end{array}$ & $\begin{array}{l}\text { Textos em smartphones } \\
\text { estão com alinhamento } \\
\text { forçado - o que gera rios } \\
\text { tipográficos ou caminhos } \\
\text { de ratos. }\end{array}$ & $\begin{array}{l}\text { Não utiliza animações } \\
\text { em Flash, por exemplo. }\end{array}$ & Primeiro link \\
\hline & Conversão & Usabilidade & Carregamento & Navegadores \\
\hline Análise & Razoável & Bom & Satisfatório & Bom desempenho \\
\hline Observações & $\begin{array}{l}\text { O Blog ou o site não } \\
\text { apresentam, de modo } \\
\text { atraente, cadastramento } \\
\text { do usuário. Não } \\
\text { apresentam CTAS em } \\
\text { diferentes telas. } \\
\text { Não há convite a } \\
\text { newsletter. }\end{array}$ & Bom & $\begin{array}{l}\text { Sugerimos avaliar } \\
\text { questão técnica } \\
\text { (tamanho de imagens, } \\
\text { carregamento parcial, } \\
\text { outros) e hospedagem. }\end{array}$ & $\begin{array}{l}\text { Marca, texto e } \\
\text { imagens estão } \\
\text { bem alocados em } \\
\text { diferentes } \\
\text { navegadores. }\end{array}$ \\
\hline
\end{tabular}

Fonte: Autores (2018)

Com os requisitos de interface analisados torna-se mais fácil a visualização do escopo da avaliação. Sendo assim, faz-se então a análise dos requisitos de acordo com o peso do perfil que a persona representa, para dar peso aos requisitos de função, criando assim, a matriz de avaliação: 
Quadro 4-Requisitos de interface

\begin{tabular}{|c|c|c|c|}
\hline MENU & $\begin{array}{c}\text { RAFAEL, } 30 \\
\text { proprietário de } \\
\text { franquia (Peso 5) }\end{array}$ & $\begin{array}{c}\text { BIANCA, } 37 \\
\text { contabilista } \\
\text { (Peso 2,5) }\end{array}$ & TOTAL \\
\hline MARCA/HOME & $5 / 25$ & $5 / 25$ & 37.5 \\
\hline QUEM SOMOS & $5 / 25$ & $5 \longdiv { 2 5 }$ & 35 \\
\hline SERVIÇOS & $5 / 25$ & $5 / 25$ & 37,5 \\
\hline NOSSOS CLIENTES & $5 / 25$ & $5 / 25$ & 30 \\
\hline CONTATO & $5 / 25$ & $5 / 25$ & 37.5 \\
\hline BLOG & $3 / 15$ & $3 / 15$ & 25 \\
\hline E-BOOKS & $1 / 5$ & $1 / 5$ & 10 \\
\hline LINKS DE REDES SOCIAIS & $2 / 10$ & $2 / 10$ & 15 \\
\hline
\end{tabular}

Fonte: Desenvolvido pelos autores (2018)

A matriz foi aplicada as personas com seus pesos a cada item dos requisitos. Cada item poderia receber uma nota de 0 a 5 . O valor final foi multiplicado pelo valor da persona. No caso de Bianca, seu valor é de 2,5. Assim, cada item dos requisitos que receberam uma nota de 0 a 5 e foram multiplicados por 2,5 (valor do peso da persona Bianca) e após foram somados com os resultados das duas personas, podendo então, ser quantificado o valor do requisito mostrando a matriz de avaliação de interface pelo peso de cada persona, o que demonstrou a importância hierárquica de cada item do site na avaliação.

Por fim, ao definir e aplicar as matrizes nas as análises da interface, os consultores perceberam oportunidades de melhorias a serem feitas na interface e essas melhorias eram sugeridas e apresentadas ao final da consultoria no item (4) Próximos passos. Estes itens são longos e extensos e não cabem serem explanados aqui neste momento.

\section{CONSIDERAÇÕES}

Foi possível notar que organizar as informações por meio de um fluxograma para interfaces digitais possibilita uma visualização facilitada de cada uma das etapas. Isso corrobora com as propostas de: Teixeira (2015) e (2018), Eppler e Platts (2009), Sibbet (2013), Finocchio Júnior (2013) e Galsworth (2005).

Pressupõe-se, ainda a partir dessa pesquisa, que quando as informações são capturadas, processadas e analisadas de forma sistemática, elas favorecem a tomada de decisão. E, inclusive, a transformação de informações em requisitos mais palpáveis, facilita o monitoramento quanto ao atendimento dos requisitos de interface. Entretanto, para validar esse pressuposto, sugere-se ainda análises de caso com grupo de controle para aprofundamento em pesquisas futuras.

Percebeu-se que o fluxograma apresentado durante as consultorias realizadas para as nove empresas teve boa aceitabilidade. Este foi percebido como ferramenta de valor prático pelos consultores, facilitando na análise a percepção e avaliação das melhorias, além de apresentá-las de forma mais fundamentada e direcionadas às interfaces analisadas.

Notou-se também que as matrizes podem ser aplicadas de forma adaptada em outros contextos projetuais, métodos, ferramentas e técnicas de avaliação, mas, para isso, 
recomendamos que alguns estudos preliminares sejam feitos. Ainda como trabalhos futuros, os autores pretendem: a) publicar as análises das outras oito empresas de forma mais detalhada como estudo de caso; b) aprimorar, avaliar e validar a proposta para defini-la como modelo em um cenário futuro; c) desenvolver uma versão do fluxograma em plataforma online para que projetistas e analistas possam utilizar e solução e que seja aprimorado com base na experiência do usuário.

Desta forma, este artigo, de modo geral, buscou ampliar o entendimento das particularidades presentes em projetos de interface através do ordenamento metodológico para propor soluções apropriadas, para o qual o designer também participa. Neste sentido, o desenvolvimento de interfaces se apresenta como um cenário desafiador para as equipes de projeto. Estas buscam conhecer o potencial dos elementos midiáticos, encontrar formas de compor visualmente e estabelecer uma lógica coerente ao usuário e condizente ao propósito de negócio.

\section{Referências}

BACK, N. et al.. Projeto integrado de produtos: planejamento, concepção e modelagem. Barueri: Malone, 2008.

BURKOLTER, D. et al. Customization of user interfaces to reduce errors and enhance user acceptance. Applied Ergonomics, v. 45, n. 2, p. 346-353, mar. 2014.

EPPLER, M.; PLATTS, K. Visual Strategizing: the systematic use of visualization in the strategicplanning process. Long Range Planning, [s.I], v. 42, n. 1, p. 42-74, 19 jan. 2009. Trimestral. Disponível em: < http://www.sciencedirect.com/science/article/pii/S0024630108001180>. Acesso em: 01 mar. 2018.

FREITAS, J. C. de. O design como interface de comunicação e uso em linguagens hipermidiáticas. In: LEÃO, L. (Org.). O chip e o caleidoscópio: Reflexões sobre as novas mídias. São Paulo: Editora Senac, 2005. p. 183-196.

FINOCCHIO JÚNIOR, F. Project Model Canvas: gerenciamento de projetos sem burocracia. Rio de Janeiro: Elsevier, 2013.

GALSWORTH, G. Visual Workplace: Visual Thinking. Portland: Visual-lean Enterprise Press, 2005

GARRETT, J. J. The elements of user experience: user-centered design for the web and beyond. Pearson Education, 2010.

ROZENFELD, H. et al. Gestão de desenvolvimento de produtos: uma referência para a melhoria do processo. São Paulo: Saraiva, 2006.

PMI. A guide to the project management body of knowledge (PMBOK). Project Management Institute, Inc - PMI, Newtown Square, 5th Edition, Pennsylvania, 2013.

SIBBET, David. Reuniões visuais: como gráficos, lembretes autoadesivos e mapeamento de ideias podem transformar a produtividade de um grupo. Rio de Janeiro: Alta Books, 2013.

SILVA, C. R. O. Metodologia e Organização do Projeto de Pesquisa: Guia Prático. Fortaleza: Centro Federal de Educação Tecnológica do Ceará, 2004. 
TEIXEIRA, J. M. Gestão visual de projetos: um modelo que utiliza o design para promover maior visualização ao processo de desenvolvimento de projetos. 2015. 330 f. Tese (Doutorado) - Curso de Curso de Engenharia de Produção, Centro Tecnológico, Universidade Federal de Santa Catarina, Florianópolis, 2015.

Gestão visual de projetos: utilizando a informação para inovar. Rio de Janeiro: Alta Books, 2018. 208 p.

TEIXEIRA, J. M.; BENEDET, G. V.; HOPPE, A. Um passo-a-passo para transformar pesquisa informacional e personas em requisitos de projeto. e-Revista Logo, Florianópolis, v. 4, n. 2, p.1-16, 2015. Quadrimestral.

TEIXEIRA, J. M.; BENEDET, G. V.; PINTO, A. L. Proposta de framework para validação de personas: um estudo com base em análise de cluster. Educação gráfica, v. 20, n. 3, p. 375-394, 2016. 